\title{
Iranian medical university board of trustees' challenges in practice: A qualitative study
}

\author{
Masoud Abolhallaje ${ }^{1}$, Hossein Ebrahimipour ${ }^{2}$, Mehdi Jafari*1, 3 (D) , Arefeh Pourtaleb ${ }^{1}$
}

Received: 29 May 2019

Published: 17 Apr 2021

\section{Abstract}

Background: Board of Trustees (BOTs) in Iranian medical universities has been considered as one of the most important structural and managerial changes to create a revolution in decision-making and accountability. This study aimed to explore challenges facing BOTs in governing Medical Universities (MUs).

Methods: In this qualitative study, 27 semi-structured interviews were conducted with current and former members of BOTs, chancellors of universities, BOTs' secretaries, and staff in the Ministry of Health and Medical Education in 2017. These participants were selected using a purposive and snowball sampling method. Data were analyzed by framework analysis and using Atlas-Ti software.

Results: Five key themes were identified, including 1) infrastructure (problems in BOT laws and membership requirement), 2) planning and decision-making (evidence-based decision making and planning and meeting), 3) organizing (ambiguity in positions and lack of necessary administrative structure), 4) performance evaluation (self-reporting, lack of time allocation, lack of evaluation criteria and lack of required structure for evaluation), 5) independence and influence on performance (dependency on the Ministry of Health and Medical Education and financial independence).

Conclusion: Due to obsolete laws, it seems that the structural and executive reform of BOTs is essential. The issues of university autonomy and empowerment of the boards' members should particularly be considered in such reforms. However, it appears that more delegation and empowering the position of the boards could be effective strategies in governance medicals universities.

Keywords: Governing board, Trustees, Qualitative study, Iran

Conflicts of Interest: None declared

Funding: The present study was supported by Iran University of Medical Sciences. Grant: 642-1391.

\section{*This work has been published under CC BY-NC-SA 1.0 license.}

Copyright $₫$ Iran University of Medical Sciences

Cite this article as: Abolhallaje M, Ebrahimipour H, Jafari M, Pourtaleb A. Iranian medical university board of trustees' challenges in practice: A qualitative study. Med J Islam Repub Iran. 2021 (17 Apr);35:50. https://doi.org/10.47176/mjiri.35.50

\section{Introduction}

Today, universities are undergoing more decisive changes than other fields. Universities have a critical role in supporting and maintaining economic growth, but they

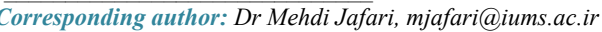

1. Health Managers Development Institute, Ministry of Health and Medical Education, Tehran, Iran

2. Social Determinants of Health Research Center, Mashhad University of Medical Sciences, Mashhad, Iran

3. Department of Health Services Management, School of Health Management and Information Sciences, Iran University of Medical Sciences, Tehran, Iran have been facing unprecedented pressure from governments and the public to improve their efficiency, quality and reduce costs (1). One of the consequences of such pres- $\uparrow$ What is "already known" in this topic:

Right now, the Board of Trustees, the most important pillar of medical universities, plays a crucial role in the university's independence. Although laws and policies authorizes notably the Board of Trustees in Iranian medical universities, still universities face serious challenges in using this authority.

\section{$\rightarrow$ What this article adds:}

Partial implementation of the Board of Trustees' policy, without paying attention to the other substantial, fundamental aspects of this issue, would end in failure. Therefore, reforms in the Board of Trustees need a comprehensive and systematic view and approach that includes law obligation, member's selection, and a structural requirement for effective performance. 
sures is managerial changes with the purpose of coordinating university activities with the needs of society, further efficiency of activities as well as earning more income. In this field, the sustainable organizational response will depend crucially on governance, leadership, and management functions (2). Several models have been created in different parts of the world for university governance, each of which has its own strengths and weaknesses (3). The most important of such models are: 1) University governance by academic staff, 2) Corporative governance, 3) Trustees governance, 4) Stakeholder governance, 5) Amalgam model of governance (3). Among these models for university governance, there has been much more attention to the role of the governing board. The governing board, which is the most important kind of boards, has been identified as the decision and policy-making group that has a position at the top of an organizational structure. The board has the highest organizational authority and is accountable for organizational activities and outcomes as well (4).

In the context of Iran, the Ministry of Health and Medical Education (MOHME) is responsible for public health, medical treatment, and medical education (5). Medical education in Iran is highly centralized. However, despite a growing tendency towards delegation and application of educational policies, the regulations and rules are still centrally dictated, and universities have had very limited authority to modify this condition (5). In this regard, particular attention has been rendered to the empowerment of the university board of trustees (BOTs) as one of such structural and managerial changes to create devolution in decision-making and accountability. However, many believe that a few years after the ratification of the BOTs' Act, the responsibilities of BOTs are not still completely specified and universities are being governed based on previous regulations (5). Since there is little literature regarding the BOTs' challenges in governing medical universities in Iran, this study aimed to determine these challenges from the experts' viewpoints.

\section{Methods}

\section{Research design}

This qualitative study was carried out in 2017, in which twenty-seven persons were selected using purposive snowball sampling. The selection criteria were as followed: being a BOTs member for at least 4 years, being a university manager for at least 4 years, participating in BOTs meetings as a MOHME expert for at least 2 years, or being BOTs' secretary in medical universities at least for 4 years.

\section{Data collection}

The participants were contacted by telephone for the interview, and then a sheet containing the purpose of the project, introduction of the researcher, and a request for the appointment was sent to them. It was tried to carry out the interview with the participants in their office or at the possible time around the BOTs meetings so that they feel more comfortable. Twenty-seven face-to-face interviews as well as five complementary interviews, were conducted by telephone. All interviews were recorded and transcribed. The average interview time was 45 to 75 minutes. The interviews were performed by one of the authors (H. E.). The questions were designed in such a way that they could inquire about the attitudes and beliefs of interviewees about the subject. First, four in-depth interviews were conducted in order to obtain a better understanding of the subject and to identify the issues that should be considered during the semi-structured interviews so that accordingly, an appropriate set of questions can be developed for these interviews.

\section{Data analysis}

The Framework Analysis method was used to analyze data that consisted of five steps of familiarization, identifying a thematic framework, indexing, charting as well as mapping and interpretation. This method of analysis is more used for analyzing qualitative data in policy-making studies. During the familiarization step, a form including information related to subjects and a content summary of each interview was developed. In order to develop the initial thematic guide form, frequent meetings were held between researchers and they discussed the topic. Then, this thematic framework was examined through frequent analysis of each of the interviews (Familiarization step).

One of the authors (H.E.) coded each interview and extracted a list of these codes from the interviews, along with their relation to the thematic framework. In this step, one or two codes were assigned to each part of the interviews containing related information. Then, these codes were studied and modified if deemed necessary through meetings with other researchers. This process was repeated several times for each of the interviews. Subsequently, tables were drawn up in order to compare the views of interviewees about each component of the thematic model and to specify the relationship between each component of the model with its subset. Where necessary, the original interviews were also referred for a better understanding of participants' statements, and the important contents were added to it. The interpretation of each of the components of the thematic model was performed within the same process as the indexing step. Atlas-Ti software was used in all mentioned steps. The Thematic Framework was frequently revised in the analysis process. The Initial Framework included five themes that remained almost unchanged; however, the subgroups of each of these thematic components were fundamentally changed during this process. Researchers provided data from field notes and memos, and in the analysis process, the authors repeatedly discussed the process of analysis. Member checking was performed during data collection, and then the researchers' interpretations were verified by the participants. Interviews and the analysis process were audited by the first author and then reviewed by the second and third author, making changes wherever needed. The prolonged engagement of researchers in the process of study strengthens the trustworthiness of the results. Furthermore, to facilitate transferability, the study process was reported in detail and representative quotations from the transcript were provided.

Ethical considerations: In this study, initial verbal consent was obtained from the interviewees. Participants 
were informed that they could decline participation at any time during the study. They were informed that their participation was confidential and voluntary, and the information used in the article would be anonymous.

\section{Results}

Participants were current and former members of BOTs of medical universities in Iran (17 persons), current and former chancellors of universities (four persons), secretaries of BOTs (four persons), and staff of the Ministry of Health who work in the related area of BOTs' affairs (two persons), respectively. The mean age of these participants was (44.8 \pm 7.34$)$ and regarding their educational level, thirteen participants were physicians, eight participants were Ph.D. and finally, six participants were MSc and BSc. The identified themes and sub-themes have been separately explained.

\section{Theme I: Infrastructures}

Laws: The current BOTs law of Iran universities has considered high and increasing authorities for boards of trustees. The problems associated with the current regulations from the perspective of the participants of this research include contradiction of laws, lack of transparency of laws, and lack of comprehensive laws.

Contradiction in Laws: Despite the stipulation of laws concerning BOTs' authority to make decisions independently and exempt from observing the common rules of the country, some decisions cannot be implemented due to conflict with other laws of the country. Two different reasons can be enumerated for this issue: 1) implementation of some decisions require the collaboration of organizations that are not aware of exemption of universities from the common laws of the country, 2) legislation of laws by Parliament that limits the given authorities to BOTs. One of the participants of the research explains this issue as follows:

"For instance, Board of Trustees approves purchase of a car from the income of university, but the Department of Finance states that this [Act] cannot be accepted and applied pending the approval of police" (P5).

Lack of Transparency of Laws: Lack of transparency of BOTs' authority has caused more conservative members or members who do not care much for the problem of universities to use it as an excuse for not entering the approval of many concerning plans. For example, one of the participants has stated:

"For example, it is stipulated in the BOTs laws that: "...decision on how to manage service units (hospitals, health departments, etc.)..." what does decision on how to manage means?" (P13)

Lack of Comprehensive Law: Due to the dispersion of regulations that exist on the authority of BOTs and lack of transparency in some of them, the authorities of BOTs in various rules should be amassed in a comprehensive law and then be approved by Parliament.

Membership: In this section, three important concepts are highlighted, including membership criteria, composition, and the number of members as well as empowerment of members.

Membership Criteria: From the participants' perspective, the criteria that should be considered in selecting the members of BOTs include:

- Allocating time to university affairs and having concern about the university

- Being indigenous

- Having managerial as well as administrative knowledge and experience

- Having political and social influence

- Having novel and diverse perspectives

Composition and Number of Members: The participants believe that the number of members is sufficient at present, and the number of members can be added if deemed necessary. The promotion of technical skills of BOTs, particularly in financial and managerial areas, should be taken into consideration. In addition, the criterion of social and political influence is too much considered in the selection of BOTs members, while politically and socially influential individuals, due to busy responsibilities, cannot be seriously involved in university issues and the university is not usually among the major personal or professional concerns for these members. Additionally, medical universities are responsible to provide health services in related provinces. Therefore, a major part of their human resources is health service providers who have currently no representative in BOTs.

"As long as the medical universities are in charge of providing health services, the health care workers should have representative in BOTs, as faculty members have" (P22).

Empowerment of Members: Many participants believed that scores of BOTs members are not familiar with their duties and at present, there is no specific arrangement to exchange experiences of BOTs members of different universities.

"The members of BOTs must be trained about their duties and should be unanimous in respect to their tasks" (P12).

\section{Theme II: Planning}

Long-term Planning: Little attention to country's longterm programs and lack of a strategic plan approved by the BOTs are among the most important problems stipulated by research participants. This problem has led to the fact that the decision-making of BOTs is not directed toward a clear objective, and furthermore there is no framework for evaluating the performance of university by BOTs. In this regard, one of the participants declares that:

"Long-term plans of university are not presented to BOTs for approval. If we have these plans, we would arrange the agendas within the framework of such longterm plans and perform evaluations based on them" (P6).

Evidence-based Decision-making: In this section, the most important part of the participants' perspective includes screening system of agenda, existence of expert committees, and passiveness of meetings.

Screening System of Agenda: The features of "lack of a 
specific screening system of agenda" included the followings: delay in sending the documentations of meetings to members prior to holding sessions, not inviting members to participate in meetings in order to study the agenda before holding BOTs meeting, high volume of documentations submitted to the BOTs and also, lack of time to review the agenda and unfamiliarity of members to the issues mentioned in documents. For example, one of the members explained this problem as follows:

"The members of BOTs should know that what the origin of discussed proposal at the meeting is. Many of such proposals have not originated from BOTs which means that they have never been discussed before in BOTs meetings" (P18).

Presence of Expert Committees: Currently, there are no permanent expert committees in BOTs. To compensate for this shortcoming, some universities, benefiting from the human resources of other parts of universities, have formed ad hoc committees. These ad hoc committees are responsible for various actions such as developing and refining the proposals of different departments, which are scheduled to be discussed in BOTs. One of the participants in this study explains the issue as follows:

"One of the weaknesses is lack of expertise team in BOTs. Given that we do not enjoy such a team, the experts from other fields should do this task; however, this relationship is not defined as well" (P4)...

Passiveness of Meetings: The findings of this section of the study contain two facts. First, the members of BOTs are always waiting for university president or Ministry of Health for holding the sessions (passive action to attend meetings) and also in respect to the agenda, the university president and board of managers define the needed issues to discuss in BOTs meeting (passive action about the agenda).

Based on the needs arising from deputies, some discussions are posed at BOTs. These deputies usually bring such issues before the president of the university and decide whether it can be discussed at BOTs based on university visions. It means that the members of BOTs act passively rather than proposing the issues themselves.

Planning of Meetings: The participants in this study believed that the number of meetings of BOTs is not sufficient, and further meetings were required. However, the problem is that the representative of the Minister must be present at all sessions. Besides, given four annual sessions to be held in all 45 universities in the country, holding further sessions is nearly impossible. Therefore, the participants believed that universities should be allowed to hold formal meetings without the presence of the Minister's representative. In addition, most sessions are held in the capital city of Tehran and this will result in the fact that the provincial members are not aware of the problems of the region where the university is located. Besides, many members fail to participate actively in the meetings because of several reasons including an overload of the agenda, lacking the pertinent expertise for evaluating the agenda, lacking a sense of identity.

For example, a number of the participants explain this issue as follows:
"We have BOTs members who have not participated even once at the meetings held in university".

"In the BOTs meeting of one of the universities, at the end of the session, we could later understand that one of the individuals attending the meeting is the member of BOTs because he had not spoken even a sentence throughout the session" (P9).

\section{Theme III: Organizing}

In this section, the most important extracted concepts included 'ambiguity in the position' and 'lack of necessary administrative structure'.

Ambiguity in the Position of BOTs: Lack of transparency of BOTs' law that defines the responsibilities of different principal units of the university (Board of Managers, University Council) would lead to an overlap of activities in some cases. In addition, some BOTs' members believe that the Board of Trustees has a superficial position in the university because they usually approve only the decisions that are presented by the Ministry of Health or various units of the university. In other words, the BOTs have no role in the strategic leadership of universities and its maximum role is to approve defined agendas by the Ministry of Health and to review and give authority to university units that have problems in conducting their current affairs or require authorization. As it was mentioned, one of the reasons of functions overlaps is the lack of transparency of law; however, it is also because of the unfamiliarity of members with their duties and lack of clarity in the interdepartmental relationships of the university. One of the participants describes it as follows:

"For example, the issue which should be discussed in university council is presented to BOTs for approval" (P18).

Lack of Necessary Administrative Structure: If the members of BOTs would like to associate with academic units, the necessary administrative structure should be defined for the Board of Trustees' office and communication channels need to be defined.

Theme IV: Performance Evaluation (Ensuring Proper Management of University)

At present, the subject of one of the annual meetings of BOTs is university performance evaluation. In this session, typically, the president and members of the university provide a report of their performance and the auditor presents a report on his/her assessments as well. Many of the participants believe that this evaluation fails to provide a genuine picture of the university's performance. Problems associated with evaluation from the perspective of BOTs members are as follows:

- Self-reporting by different sections of university and the inability of members to verify it

- Lack of time allocation by BOTs' members to attend university and familiarization with the plans

- Lack of evaluation criteria due to lack of approved long-term programs at university (passiveness in the face of reports)

- Lack of required infrastructure and tools for evaluation in BOTs such as needed technical committees. 
Theme V: Independence and its Effect on Performance

Affiliation with the Ministry of Health: One of the main reasons for BOTs' establishment in Iran is universities' independence and avoidance of the dominated bureaucracy on their affairs. From the perspective of the participants in this study, the BOTs currently have no actual independence and what they have is superficial independence. The main reason for this is that the BOTs have no right and authority to select university president and the legality of BOTs decisions is pertaining to the approval of MOHME.Due to various reasons such as the need for complying with the course of action of universities with the country's general policies, MOHME is reluctant to delegate authority to universities. In addition, it is believed that currently, BOTs members are not capable of running universities.

Attracting Financial Resources: The decrease of dependence on government sources, from the participants' views, has a high priority for the autonomy of universities. However, it is believed that the BOTs are not successful in terms of the universities' financial independence. Some actions were taken by universities (e.g., the use of donors' support) have no direct connection with the activities of BOTs. The reasons for this include lack of adequate attention to donors, lack of time allocation by BOTs members to attract funds, lack of a proper platform for attracting public donations in BOTs and distrust of some donors to governmental systems.

\section{Discussion}

The findings indicate that with new legislation in recent years as well as delegating authority to BOTs of medical universities, a major part of the BOTs' problems for university management is solved. However, given the outdated initial laws of BOTs and the changing national and international conditions, there is still a need for new legislation to complete such authorities. In addition, the application of such authorities has encountered many challenges due to reasons such as conflicts of BOTs laws with common rules of the country as well as challenges that the BOTs' organizations face to coordinate with each other (6). Therefore, it is recommended to enact comprehensive legislation for BOTs in which the present chasms are wellconsidered and amended, including the followings:

- Considering the issue of providing health services in BOTs laws of MUs.

- Considering the central dimensions of university administration, such as planning and policy-making as well as evaluation-related tasks

- Independence and accountability of BOTs (7)

- Exactly defining of the position of BOTs in universities, especially in relation to other principal structures such as university board of managers and university council

- Clarification of monitoring and the coordinating task of MOHME

- The issue of selection and dismissal of university president (8)

In addition, the contradiction of BOTs authority laws with some of the country's regulations should be removed (6). After the passage of this legislation, it would be required to formulate necessary guidelines so that the BOTs are empowered to use legal authority (9).

Lack of sufficient time allocated by BOTs is among the identified problems in this study. The results of other studies confirm this issue, which could be due to a number of reasons: first, these members believe that their position is not prominent in the management of the university. In fact, they assume that their absence does not make considerable changes in university performance; second, such members do not consider the task of BOTs as their main concerns; third, the members may not be aware of the importance of their role in university management. Lack of allocation of time is further witnessed (10), especially among the members who have joined BOTs due to social and political status. In addition, when selecting the members, the issue of knowledge and experience, commitment, individual capabilities as well as being indigenous should be considered (10). Therefore, it is generally recommended to make use of influential political figures through other means (such as an honorary membership), and there is no need for their permanent membership in BOTs.

The problem of insufficient time allocation, poor and ineffective participation in university activities and meetings, and the replacement of BOTs members are the common challenges which have been seen in other university BOTs' experiences. However, up to the time that the duty of providing health services is the responsibility of medical universities, the presence of health service provider representatives' members seems to be necessary for BOTs composition in addition to representative members from academia (3).

The members, especially those who join the BOTs from outside medical universities, should be empowered through training courses or other means. In such sessions, familiarization with university tasks, duties of BOTs members, financial issues, laws, and regulations related to universities and other country's statutory regulations can be provided $(11,12)$.

Lack of expert committees for the screening of agendas and helping decision-making system is among the existing problems of BOTs. Conducting a part of the present duties of BOTs, particularly monitoring the performance of the university president as well as financial affairs, requires a permanent committee to change the university performance evaluation from the state of mere self-reporting by the university president (13). In this regard, the proposed committees, according to international experiences, include executive, budget and finance, buildings and lands, auditing, evaluation, human resources, development and public relations (14).

Lack of a university roadmap is also one of the main problems noted by participants. This roadmap determines the overall direction of university activities as well as priorities. It can convert the passive decision-making process into an active one, which can provide a framework for innovation in need-based planning (9). In addition, according to this roadmap, it can be determined whether the 
BOTs agenda is in line with this plan. Also, the existence of a roadmap helps develop the screening system of agenda and provides BOTs members with valid criteria for the assessment of university activities on the basis of which they can evaluate the performance of university managers (9).

Low meetings is another problem reported in this study that is consistent with other studies $(11,15,16)$. However, holding specialized sessions is part of successful reforms recently done by the Ministry of Health in this area. Accordingly, in addition to increasing the number of sessions and allowing universities to hold a session with specific issues ( 9 to 12 sessions), it is recommended to hold such meetings on the university campuses in order to involve BOTs' members more than ever. As mentioned in previous discussions, the ability to attend meetings should be considered as one of the selection criteria of BOTs members.

The findings suggest that BOTs aren't satisfied with their current independence, and they formally and informally are subordinated to the policies of the Ministry of Health and university managers. This issue is also among the results of other studies $(17,18)$. The main indexes of lack of BOTs independence include the following items: the selection of university president, lack of financial independence, employment, and MOHME permission requirement to verify BOTs decisions. But legally, it has been clearly stipulated in BOTs law and BOTs have this right and responsibility (19). One of the most important needed actions is financial independence and universities should not be just financially dependent on the government $(9,14)$. In this regard, enabling the option of donors' aid is suggested as a means to increase the income of universities.

The argument given for the lack of university independence is that with the current situation, BOTs are not able to manage universities. In addition, the independence of universities may result in noncompliance of university policies with the general policies of the country in the field of science and technology as well as providing health services (20). Therefore, some countries prefer the subordination of universities to government or ministry of science planning (20). In order to solve this problem, it is suggested to establish centralized BOTs in the Ministry of Health to decide on such policies, as there are some experiences in this field (20).

One of the main tasks of BOTs is the evaluation of institution performance (11). At present, monitoring of university president activities is mostly conducted through a self-reporting system, and there is no approved clear and comprehensive structure. In order to ensure proper management of the institution the BOTs, while regulating stronger mechanisms of performance evaluation (in addition to the auditor's and university president's report), should create monitoring and evaluation mechanisms for the performance of the university president and subunits (13). However, its prerequisite is the allocation of enough time to the issue at hand. The existence of long-term approved plans, as well as permanent specialized committees, can be helpful in this regard.

\section{Limitations of the study}

In designing this study, all the best effort has been made to involve the most informed participants about BOTs' issue who had job experience in this field. This study had some potential limitations that may affect the results. Some participants may not have expressed their real views and concerns due to various reasons such as unacceptability of their views from a political point of view and dissimilarity of their opinions with the BOTs chairperson. In addition, although it was believed that the viewpoints of the BOTs chairperson of the Ministry of Health could make a major contribution to the study, we failed to interview him due to his pre-engagements.

\section{Conclusion}

The structural and functional reforms of university BOTs affiliated with the Ministry of Health and Medical Education seem to be indispensable due to obsolete BOTs regulations and the difference between medical universities and other universities regarding their functions in providing health services. Hence, the policy-makers, while believing in the autonomy of universities and commitment to this issue, must embark on a comprehensive, transparent legal approach. By using this pervasive approach, the authorities of BOTs members are increased, and their empowerment, as well as their selection method, are taken into consideration so that the independence of universities' performance, as the main objective of BOTs existence in universities, would be achieved.

\section{Acknowledgment}

The authors would like to thank the Central Secretariat of the Board of Trustees of the Ministry of Health and also the Budgeting and Performance Monitoring Center in Iran Ministry of Health and Medical Education. Our special thanks to all boards of the trustees' members who participated in this study. We also thank the members involved in the research department of Iran University of Medical Sciences.

\section{Conflict of Interests}

The authors declare that they have no competing interests.

\section{References}

1. Boer H, File J. Higher education governance reforms across Europe. Brussels: ESMU. 2009

2. Inayatullah S, Milojevic I. Leadership and governance in higher education 2025: can Malaysian universities meet the challenge? Foresight. 2016;18(4): 434-40.

3. Trakman L. Modelling university governance. High Educ Q. 2008;62(1 2):63-83

4. Azar FE, Asiabar AS. Does leadership effectiveness correlates with leadership styles in healthcare executives of Iran University of Medical Sciences. Med J Islam Repub Iran. 2015;29:166.

5. Shattock M. University governance, leadership and management in a decade of diversification and uncertainty. High Educ Q. 2013;67(3):217-33

6. Doshmangir L, Rashidian A, Ravaghi H, Takian A, Jafari M. The experience of implementing the board of trustees' policy in teaching hospitals in Iran: an example of health system decentralization.Int J Health Policy Manag. 2015;4(4):207.

7. Damari B, Aminloo H, Farzan H, Rahbari M, Alikhani S. Ways to 
improve the current performance of the boards of trustees of Medical Universities in Iran. Iran J Public Health. 2013;42(1):36.

8. Bikmoradi A. Exploring academic leadership in medical schools and universities in Iran: Institutionen för lärande, informatik, management och etik, LIME/Department of Learning, Informatics, Management and Ethics (Lime); 2009.

9. Jafari M, Habibirad A, Pourtaleb A, Salarianzadeh MH. Health system organizational reform in governing Iranian public hospitals: A content analysis to comprehend the barriers in Board of Trustees' hospitals. Int J Health Plann Manage. 2018;33(2):e612-e20.

10. Ingley CB, Van der Walt NT. The strategic board: The changing role of directors in developing and maintaining corporate capability. Corp Gov. 2001;9(3):174-85.

11. Damari B, Rahbari-Bonab $\mathrm{M}$, Aminloo H. Challenges and Performance Improvement Approaches of Boards of Trustees of Universities of Medical Sciences and Health Services in Iran. Hakim Res J. 2014;17(2):88-95.

12. Schaefer N. The big snooze: How college trustees are failing their universities. Am Enterp. 2002;13(6):32-7.

13. Sajadi HS, Maleki M, Ravaghi H, Farzan H, Aminlou H, Hadi M. Evaluation of board performance in Iran's universities of medical sciences. Int J Health Policy Manag. 2014;3(5):235.

14. Kabir MJ, Abolhallaje M, Bastani P, Keshavarzi A. Necessary Requirements for Implementation of Financial Reform in the Iranian Health Sector. Health Scope. 2017;6(3).

15. Hamdhaidari S, Agahi H, Papzan A. Higher education during the Islamic government of Iran (1979-2004). Int J Educ Dev. 2008;28(3):231-45.

16. Jafari M, Rashidian A, Abolhasani F, Mohammad K, Yazdani S, Parkerton P, et al. Space or no space for managing public hospitals; a qualitative study of hospital autonomy in Iran. Int J Health Plann Manage. 2010;26:(N/A).

17. Michael SO, Schwartz M, Cravcenco L. Evaluating higher education leadership: indicators of trustees' effectiveness. Int J Educ Manag. 2000;14(3):107-19.

18. O'BANION T. Damage caused by the rogue trustee. Community Coll J Res Pract. 2009;33(7):547-63.

19. Sadeghifar J, Bahadori M, Baldacchino D, Raadabadi M, Jafari M. Relationship between career motivation and perceived spiritual leadership in health professional educators: a correlational study in Iran. Glob J Health Sci. 2014;6(2):145.

20. Sajadi HS, Maleki M, Ravaghi H, Hadi M. Evaluating the University's Governing Board: A Comprehensive Review of Its Domains and Indicators. Am. J Educ Res. 2014;2(10):892-7. 